\title{
Application of cellulose-immobilized riboflavin as a redox mediator for anaerobic degradation of a model azo dye Remazol Golden Yellow RNL
}

\author{
Luide Rodrigo Martins $^{\mathrm{a}}$, Bruno Eduardo Lobo Baêta ${ }^{\mathrm{b}}$, Leandro Vinícius Alves Gurgel ${ }^{\mathrm{b}}$, \\ Sérgio Francisco de Aquino ${ }^{\mathrm{b}}$, Laurent Frédéric Gil ${ }^{\mathrm{b}, *}$ \\ ${ }^{a}$ Environmental Engineering Post-Graduate Program, Federal University of Ouro Preto, Ouro Preto, MG, Brazil \\ ${ }^{\mathrm{b}}$ Department of Chemistry, Institute of Biological and Exact Sciences, Federal University of Ouro Preto, Ouro Preto, MG, Brazil
}

\section{A R T I C L E I N F O}

\section{Article history:}

Received 29 July 2014

Received in revised form 17 October 2014

Accepted 27 October 2014

Available online 13 November 2014

\section{Keywords:}

Riboflavin

Succinylated cellulose

Immobilized redox mediator

Remazol Golden Yellow RNL

Anaerobic treatment

\begin{abstract}
A B S T R A C T
This study described the anaerobic degradation of the azo dye Remazol Golden Yellow RNL (RGY-RNL) using cellulose-immobilized riboflavin (MC 3) as the redox mediator. This new solid support containing immobilized riboflavin was synthesized from succinylated mercerized cellulose, and was characterized by elemental analysis, FTIR, and solid-state ${ }^{13} \mathrm{C}$ NMR. MC 3 was resistant to $\mathrm{pH} 2-9$, and anaerobic degradation of RGY-RNL using MC 3 in the presence of anaerobic sludge yielded a zero order degradation rate constant $\left(k_{0, \text { obs }}\right)$ equal to $0.189 \mathrm{mg} / \mathrm{Lh}$, which was $56 \%$ better than experiments carried out without a redox mediator. Color removal efficiency after $48 \mathrm{~h}$ of degradation averaged $89.4 \%$ in experiments with MC 3 and 72\% without the addition of a redox mediator. These results showed that MC 3 can be used to immobilize redox mediators, allowing reduction of wastewater treatment costs.
\end{abstract}

(c) 2014 Elsevier B.V. All rights reserved.

\section{Introduction}

Highly-colored effluents generated by different types of industries, especially the textile sector, are a matter of great environmental interest (Field and Brady, 2003; Méndez-Paz et al., 2005). The textile industry employs several steps to give the fabrics the properties and characteristics desired in the final product, of which dyeing is one of the most important, and it is estimated that $10-15 \%$ of dyes used in the dyeing process do not adhere to the fibers and end up in the textile effluent (Corrêa et al., 2009). Apart from their potential toxicity, dyes and pigments are recalcitrant (resistant to degradation) and may remain in the environment for long periods, accumulating in water and soil if not suitably treated before being discharged (dos Santos et al., 2007).

Most dyes used for textile industries (60-70\%) are aromatic azo compounds, which bear the functional group $\mathrm{R}-\mathrm{N}=\mathrm{N}-\mathrm{R}^{\prime}$, in which $\mathrm{R}$ and $\mathrm{R}^{\prime}$ are usually substituted aromatic compounds (van der Zee et al., 2003). Azo dyes are removed by a non-specific reduction mechanism under anaerobic conditions, but the low rate of degradation is the primary issue when adopting anaerobic reactors to

\footnotetext{
* Corresponding author. Tel.: +55 313559 1717; fax: +55 3135511707.

E-mail address: laurent@iceb.ufop.br (L.F. Gil).
}

remove these compounds from industrial wastewater (van der Zee et al., 2001a).

Studies have indicated the main limitation for azo dye reduction under anaerobic conditions is transferring the reducing equivalents generated by the cells during the metabolic process to the azo dye (Field and Brady, 2003). Redox mediators (RM) such as riboflavin and quinone groups, can improve this electron transfer, and studies have been performed to find cheap sources of such catalysts or for immobilizing them onto solid supports (Alvarez et al., 2010; Cervantes et al., 2011; dos Santos et al., 2004; Field and Brady, 2003; Martínez et al., 2013). Riboflavin is soluble in water and normally lost in the treated wastewater, while immobilization onto an insoluble solid support would reduce costs by allowing the recovery and reuse of riboflavin.

Cellulose is the most abundant renewable biopolymer in nature. This homopolymer of $\beta$-D-glucopiranose units can undergo chemical modifications through the reaction of its primary and secondary hydroxyl functional groups, and such chemical modifications have yielded new materials with specific physicochemical properties (Alvarez et al., 2010). Gurgel et al. (2008) and Gurgel and Gil (2009) prepared modified cellulose containing internal carboxylic acid anhydride functional groups through the reaction of succinylated cellulose (containing carboxylic acid groups) with acetic anhydride. Such functional groups are excellent electrophiles that can react with nucleophilic compounds containing amine or hydroxyl 
functional groups, resulting in the formation of amide or ester linkages on the modified cellulose.

In this study, succinylated mercerized cellulose was reacted with acetic anhydride to yield internal carboxylic acid anhydride functional groups used to incorporate riboflavin (Rib) onto the solid support through the formation of ester linkages. The efficiency of this new solid support as a redox mediator was evaluated during anaerobic degradation of the model azo dye Remazol Golden Yellow RNL (RGY-RNL).

\section{Materials and methods}

\subsection{Materials}

Microcrystalline cellulose and sulfanilic acid ( $\geq 99.0 \%$ ) were purchased from Sigma-Aldrich (cat. No. 31,069-7 and S5263, respectively, Brazil). Riboflavin (Fig. 1a), succinic anhydride, acetic anhydride, acetic acid, pyridine, sodium hydroxide, ethanol, acetone, and methylene chloride were purchased

(a)<smiles>[R10][C@@H](O)[C@H](O)[C@H](O)Cn1c2nc(=O)[nH]c(=O)c-2nc2cc(C)c(C)cc21</smiles><smiles>CC(=O)Nc1cc(N)c(S(N)(=O)=O)cc1N=Nc1ccc(OCCOS(=O)(=O)O[Na])cc1</smiles>

Remazol Golden Yellow RNL

(b)<smiles>CCCC(C)O</smiles>

Mercerized cellulose (MC)<smiles>CCCCC(C)OC(=O)CCC(=O)OCC</smiles><smiles>CC(=O)OC(C)=O</smiles>

MC 1<smiles>CCCCCCC(=O)OC(=O)CCC(=O)OC(=O)CCC(=O)O</smiles>

MC 2<smiles>Cc1ccc(F)cc1</smiles>

(c)

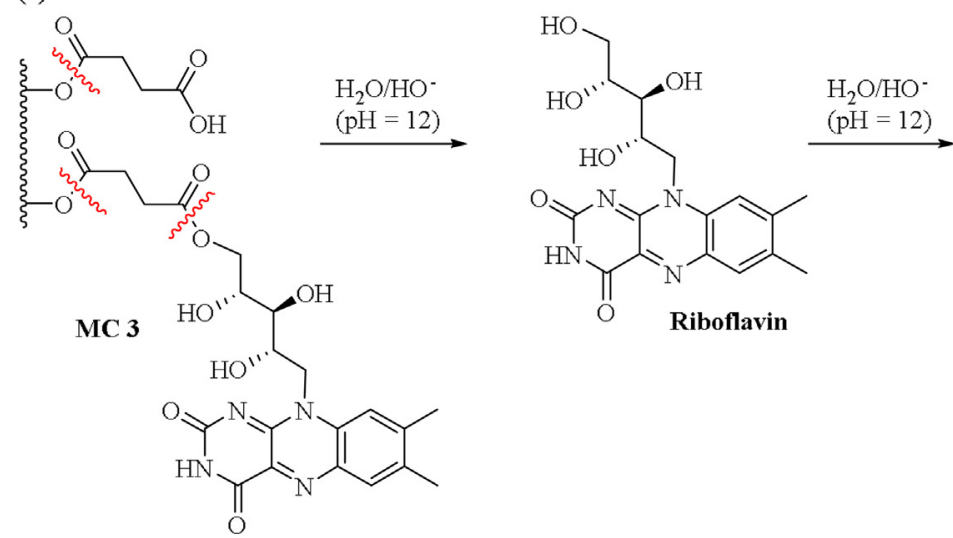<smiles>Cc1cc2nc3c(=O)[nH]c(=O)nc-3n(C)c2cc1C</smiles>

Fig. 1. (a) chemical structures of riboflavin (Rib) and Remazol Golden Yellow RNL (RGY-RNL) azo dye, (b) synthetic route used to incorporate riboflavin onto mercerized cellulose and (c) treatment used to hydrolyze (at pH 12) riboflavin attached onto MC 3 yielding lumiflavin. 
from Vetec (Brazil). Hydrochloric acid, diethyl ether, $N, N^{\prime}-$ dimethylformamide (DMF), and dimethylsulfoxide (DMSO) were purchased from Synth (Brazil). Remazol Golden Yellow RNL (RGYRNL, $\mathrm{C}_{16} \mathrm{H}_{18} \mathrm{~N}_{4} \mathrm{O}_{10} \mathrm{~S}_{3} \mathrm{Na}_{2}$, Fig. 1a) azo dye was kindly provided by a local textile industry and used without further purification. Yeast extract containing $50 \mu \mathrm{g} / \mathrm{g}$ of riboflavin was purchased from Himedia.

\subsection{Apparatus and operational conditions}

Flat-bottom amber glass bottles $(250 \mathrm{~mL})$ with polypropylene caps were used as reactors and inoculated with anaerobic sludge from a small-scale UASB reactor at the Center of Research and Training on Sanitation (CePTS) UFMG/COPASA, located at the Arrudas Wastewater Treatment Plant (WWTP) in Belo Horizonte, Brazil. The nutrient solution contained glucose (except in the experiments 5 , 10, and 11), RGY-RNL (except in the experiments 1-3), yeast extract (except in the experiments $1-4$ and 6-11), riboflavin (except in the experiments 1, 2, 4, and 8-11) and a macronutrient solution (composition is described in Supplementary Table 1). Redox mediators tested were MC 3 (cellulose-immobilized riboflavin), riboflavin and yeast extract (containing $\sim 50 \mu \mathrm{g}$ riboflavin per $\mathrm{g}$ of yeast extract). The efficiency of color removal following Remazol Golden Yellow RNL degradation was assessed by measuring the absorbance $\left(\lambda_{\max }=410 \mathrm{~nm}\right)$ of the centrifuged suspension with a UV-vis spectrophotometer (model HP 8453).

\subsubsection{Methods}

The experiments (except the modification of microcrystalline cellulose) were performed in triplicate. Pyridine was refluxed with $\mathrm{NaOH}$ pellets overnight and distilled. $N, N^{\prime}$-Dimethylformamide (DMF) was treated with 4 Å molecular sieves (Merck) overnight and distilled under reduced pressure. Succinic anhydride, acetic anhydride, and dimethyl sulfoxide (DMSO) were used without further purification.

\subsubsection{Chemical modification of microcrystalline cellulose}

2.2.2.1. Mercerization. Microcrystalline cellulose (15 g) was added to a polyethylene beaker containing $400 \mathrm{~mL}$ of $20 \%(\mathrm{w} / \mathrm{v}) \mathrm{NaOH}$ and the suspension stirred for $18 \mathrm{~h}$ at $25^{\circ} \mathrm{C}$. The suspension was filtered (sintered disk filter funnel, porosity 3 ) and the retentate washed with distilled water until $\mathrm{pH} 7$ was reached in the wash. The mercerized microcrystalline cellulose (MC) was washed with 95\% ethanol and dried at $85^{\circ} \mathrm{C}$ for $90 \mathrm{~min}$.

2.2.2.2. Preparation of MC 1. MC (11.66 g) and succinic anhydride $(34.8 \mathrm{~g})$ were placed in a round-bottom flask, anhydrous pyridine
$(233 \mathrm{~mL})$ added and the suspension heated at $120^{\circ} \mathrm{C}$ with constant stirring for $6 \mathrm{~h}$. The succinylated mercerized cellulose (MC 1) was separated by filtration (sintered glass funnel, porosity 3 ) and washed successively with a solution of $1 \mathrm{~mol} /$ Lacetic acid in methylene chloride, $95 \%$ ethanol, distilled water, $0.01 \mathrm{~mol} / \mathrm{L} \mathrm{HCl}$, distilled water, and acetone. The MC 1 was dried at $80^{\circ} \mathrm{C}$ for $1 \mathrm{~h}$.

2.2.2.3. Preparation of MC 2. MC 1 (9.4 g) and acetic anhydride $(265 \mathrm{~mL})$ were added to a round-bottom flask and heated at $100^{\circ} \mathrm{C}$ for $24 \mathrm{~h}$ with constant stirring. The suspension was separated by filtration (sintered glass funnel, porosity 3), washed with diethyl ether (previously treated with a $4 \AA$ molecular sieve) and dried at $100^{\circ} \mathrm{C}$ for $20 \mathrm{~min}$.

2.2.2.4. Preparation of MC 3. MC 2 (produced from $9.4 \mathrm{~g}$ of MC 1 ) and riboflavin $(2.35 \mathrm{~g})$ were placed in a round-bottom flask, anhydrous DMF $(140 \mathrm{~mL})$ added and the suspension heated at $75^{\circ} \mathrm{C}$ for $24 \mathrm{~h}$ under constant magnetic stirring. MC 3 was separated by filtration (sintered glass funnel, porosity 3), washed with DMF, DMSO, an excess of distilled water, 95\% ethanol, and acetone, and dried at $80^{\circ} \mathrm{C}$ for $30 \mathrm{~min}$. The water wash was monitored at $267 \mathrm{~nm}$ using an UV-vis spectrophotometer, which corresponded to the maximum absorption of riboflavin in aqueous medium. The synthetic route used to prepare MC 3 is shown in Fig. 1.

\subsubsection{Characterization of the materials}

The synthetized materials (previously dried in an oven at $90^{\circ} \mathrm{C}$ ) were characterized by weight gain, elemental analysis, FTIR and ${ }^{13} \mathrm{C}$ NMR. For FTIR characterization, $1 \mathrm{mg}$ of the material was mixed with $100 \mathrm{mg}$ of $\mathrm{KBr}$ (spectroscopy grade) and spectra recorded from 400 to $4000 \mathrm{~cm}^{-1}$ with 32 scans at a resolution of $4 \mathrm{~cm}^{-1}$. Elemental analysis was performed on a CHNS/O Perkin Elmer Series II, model 2400 analyzer. ${ }^{13} \mathrm{C}$ NMR (solid state) of MC 3 was recorded on a Bruker Avance III-400 spectrometer at room temperature and measurements obtained at frequencies of $100 \mathrm{MHz}$ with magic angle spinning of $5 \mathrm{kHz}$ using the CPTOSS technique.

\subsubsection{Evaluation of chemical stability of $M C 3$ as a function of $p H$}

As ester functional groups (used to incorporate riboflavin onto MC 3) can be hydrolyzed at $\mathrm{pH}$ values below 2 and greater than 9 , the chemical stability of MC 3 was assessed in aqueous solutions as a function of $\mathrm{pH}$. For this, $20.0 \mathrm{mg}$ portions of MC 3 were added to $250 \mathrm{~mL}$ Erlenmeyer flasks, $100.0 \mathrm{~mL}$ of $\mathrm{HCl}$ or $\mathrm{NaOH}$ aqueous solutions at $\mathrm{pH} 2,9,12$, or 14 were added to individual flasks and stirred $(100 \mathrm{rpm})$ for $24 \mathrm{~h}$ at $25^{\circ} \mathrm{C}$. The suspensions were separated by filtration (sintered glass funnel, porosity 3 ) and thoroughly washed with distilled water. The absorbance of the

Table 1

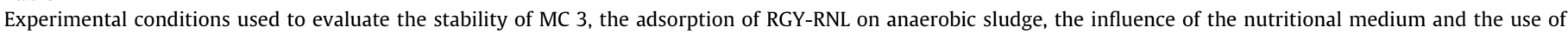
different redox mediators on color removal.

\begin{tabular}{|c|c|c|c|c|c|c|}
\hline Experiment & $\begin{array}{l}\text { MC } 3 \text { concentration } \\
(\mathrm{mg} / \mathrm{L})\end{array}$ & $\begin{array}{l}\text { Riboflavin } \\
\text { concentration (mg/L) }\end{array}$ & $\begin{array}{l}\text { Yeast extract } \\
(\mathrm{mg} / \mathrm{L})\end{array}$ & $\begin{array}{l}\text { Glucose concentration } \\
(\mathrm{mg} / \mathrm{L})\end{array}$ & $\begin{array}{l}\text { Biomass concentration } \\
(\mathrm{mg} / \mathrm{L})\end{array}$ & $\begin{array}{l}\text { Nutrient solution } \\
(\mathrm{mL})\end{array}$ \\
\hline 1 (Control) $)^{a}$ & - & - & - & 250 & 650 & 10 \\
\hline $2^{\mathrm{a}}$ & 50 & - & - & 250 & 650 & 10 \\
\hline $3^{a}$ & - & 3.56 & - & 250 & 650 & 10 \\
\hline $4(\text { Control })^{b}$ & - & - & - & 250 & 650 & 10 \\
\hline $5^{\mathrm{b}}$ & 0.245 & - & - & 250 & - & 10 \\
\hline $6^{\mathrm{b}}$ & 0.245 & - & - & - & - & - \\
\hline $7^{\mathrm{a}, \mathrm{b}}$ & 0.245 & - & - & - & $650^{c}$ & 10 \\
\hline $8(\text { Control })^{\mathrm{b}}$ & - & - & - & 250 & 650 & 10 \\
\hline $9^{\mathrm{b}}$ & - & - & 350 & - & 650 & 10 \\
\hline $10^{\mathrm{b}}$ & 0.245 & - & - & 250 & 650 & 10 \\
\hline $11^{\mathrm{b}}$ & - & 0.0175 & - & 250 & 650 & 10 \\
\hline
\end{tabular}

\footnotetext{
a Concentration of biomass (expressed as volatile suspended solids-VSS) in the stock anaerobic sludge $=12.66 \mathrm{~g} / \mathrm{L}$.

b Remazol Golden Yellow RNL concentration was $50 \mathrm{mg} / \mathrm{L}$ in all reaction flasks.

c The biomass was autoclaved.
} 
washes was measured on a UV-vis spectrophotometer (model HP 8453 ) at $267 \mathrm{~nm}$ and $354 \mathrm{~nm}$, which corresponded to the maximum absorbance wavelengths of riboflavin in acidic and basic aqueous media, respectively.

\subsubsection{Determination of riboflavin concentration on $M C 3$}

Riboflavin in aqueous solutions $\mathrm{pH} 9$ and above, is predominantly in the form of lumiflavin (Fig. 1c) (Penzkofer, 2012). The amount of riboflavin incorporated on MC 3 was assessed by hydrolyzing the ester bond used to attach riboflavin onto the succinylated mercerized cellulose at basic pH. MC $3(31.0 \mathrm{mg})$ was placed in a $250 \mathrm{~mL}$ Erlenmeyer flask, $50.0 \mathrm{~mL}$ of a $0.1 \mathrm{~mol} / \mathrm{L} \mathrm{NaOH}$ solution ( $\mathrm{pH} 12$ ) added and shaken ( $100 \mathrm{rpm}$ ) for $24 \mathrm{~h}$ at $25^{\circ} \mathrm{C}$. The suspension was centrifuged and the absorbance of the yellowish supernatant was measured on a UV-vis spectrophotometer at $354 \mathrm{~nm}$, the maximum absorption wavelength $\left(\lambda_{\max }\right)$ for lumiflavin at $\mathrm{pH} 12$, and the concentration of lumiflavin estimated by comparison to a calibration curve.

\subsubsection{Evaluation of the stability of $M C 3$ in the reaction flaks}

To verify the chemical stability of MC 3 under the experimental conditions used, experiments were carried out in the presence of all components of the reaction medium (with exception of RGYRNL), and Table 1 shows the experimental conditions used. After the incubation period ( 24 or $48 \mathrm{~h}$ ), samples were removed, centrifuged and the absorbance measured on a UV-vis spectrophotometer at 267 and $354 \mathrm{~nm}$, the maximum absorption wavelengths $\left(\lambda_{\max }\right)$ for riboflavin in acidic and basic aqueous media, respectively.

\subsubsection{Influence of the reaction medium on the degradation of RGY-RNL dye}

Experiments were performed to determine whether color removal occurred by adsorption of RGY-RNL onto the anaerobic sludge by inoculating flasks with autoclaved $\left(121^{\circ} \mathrm{C}\right.$ for $\left.20 \mathrm{~min}\right)$ anaerobic sludge. The influence of reaction medium components (e.g. nutrient solution) and whether their adsorption onto MC 3 affected color removal efficiency were also evaluated. Experimental conditions are described in Table 1.

\subsubsection{Anaerobic degradation of Remazol Golden Yellow RNL $(R G Y-R N L)$}

Experiments were performed to (1) evaluate the influence of MC 3 on anaerobic degradation of Remazol Golden Yellow RNL, (2) compare the performance of MC 3 in relation to well-known redox mediators (riboflavin and yeast extract), and (3) investigate the contribution of RGY-RNL adsorption onto MC 3 and/or anaerobic sludge. All experiments were carried out in triplicate and the degradation of Remazol Golden Yellow RNL was monitored by measuring the absorbance of the supernatants at $410 \mathrm{~nm}$ after centrifugation at $3600 \mathrm{rpm}$ for $20 \mathrm{~min}$.

Batch experiments were performed in inoculated reaction flasks with a total volume of $200 \mathrm{~mL}$ (nutritional conditions shown in Supplementary Table 1, Chernicharo (2007)) and experimental conditions set so the COD:N:P ratio was $\sim 350: 5: 1$ (concentration of macro- and micronutrients in the solution according to Aquino et al., 2007). The concentration of anaerobic biomass (collected from a small-scale UASB reactor fed with sewage) was estimated by analysis of volatile suspended solids (VSS) according to APHA (Clesceri et al., 1998). The initial concentration of biomass, RGYRNL and yeast extract in the reaction flasks were fixed at $650 \mathrm{mg} / \mathrm{L}$, $50 \mathrm{mg} / \mathrm{L}$, and $350 \mathrm{mg} / \mathrm{L}$, respectively. Concentrations of glucose, RGY-RNL, yeast extract, nutrient solution, and microorganisms in the reaction flasks were determined from optimization studies realized in our research group. In experiments performed with riboflavin or MC 3 as the redox mediators, the amount of riboflavin was proportional to that contained in reaction flasks in which yeast extract was used as the redox mediator. Control flasks were inoculated with active biomass without the redox mediator (RM).

All reaction flasks were purged with nitrogen (White Martins, 99.999\% purity), sealed, incubated at $25^{\circ} \mathrm{C}$ with mechanic stirring ( $150 \mathrm{rpm}$ ) and monitored for $48 \mathrm{~h}$ by sampling (sampling frequency varied with the type of experiment) $3 \mathrm{~mL}$ of the content by using plastic syringes. Table 1 shows the conditions used in batch experiments for the anaerobic degradation of Remazol Golden Yellow RNL assisted by redox mediators (riboflavin, yeast extract, and MC $3)$.

\subsubsection{Aromatic amines analysis}

Aromatic amines generated in the anaerobic degradation of Remazol Yellow Gold RNL were analyzed by high performance liquid chromatography (HPLC) using Shimadzu chromatography equipped with a diode array UV-vis detector set at $191 \mathrm{~nm}$ and an ion exchange column Aminex HPX-87H $(300 \times 7.8 \mathrm{~mm}$, BioRad) at $55^{\circ} \mathrm{C}$ with $0.01 \mathrm{~mol} / \mathrm{L} \mathrm{H}_{2} \mathrm{SO}_{4}$ as eluent and a flow rate of $0.6 \mathrm{~mL} / \mathrm{min}$ according to Baêta et al. (2013). Samples were centrifuged before injection $(30 \mu \mathrm{L})$. The separated aromatic amines generated as byproducts of sulfonated azo dye degradation (e.g. sulfanilic acid derivatives) can be detected at $191 \mathrm{~nm}$ according to Pinheiro et al. (2004).

\section{Results and discussion}

\subsection{Synthesis and characterization of solid supports}

\subsubsection{Synthesis and characterization of MC 1}

Microcrystalline cellulose was mercerized to convert cellulose I into cellulose II. This rearrangement of crystal packing increases the separation of chains, providing easier access to the hydroxyl groups of cellulose, reducing packing efficiency, facilitating penetration of succinic anhydride, promoting a higher degree of substitution and more uniform succinylation due to a greater number of available hydroxyl groups (Gurgel et al., 2008). Mercerized microcrystalline cellulose was reacted with succinic anhydride using pyridine as the solvent and catalyst, which yielded succinylated mercerized cellulose (MC 1) (Gurgel et al., 2008). The weight gain percentage after succinylation was calculated as follows:

$\operatorname{wgp}(\%)=\left(\frac{m_{f}-m_{i}}{m_{i}}\right) \times 100$

where $m_{f}(\mathrm{~g})$ is the weight of modified mercerized cellulose and $m_{i}$ is the weight of mercerized cellulose.

The weight gain percentage (wgp) obtained after succinylation was $105.2 \%$, due to the incorporation of succinyl functional groups through the formation of ester linkages with the primary and secondary hydroxyl groups of cellulose, which released carboxylic acid groups (Fig. 1b). The number of carboxylic groups $\left(n_{\mathrm{COOH}}\right)$ released after succinylation reaction was estimated at $7.1 \mathrm{mmol} / \mathrm{g}$ by backtitration (Karnitz et al., 2007).

MC 1 was characterized by FTIR, and the spectra of MC and MC 1 are shown in Fig. 2a. When comparing the FTIR spectrum of MC 1 with the spectrum of unmodified mercerized cellulose (MC), the appearance of bands at 2964 and $2924 \mathrm{~cm}^{-1}$ can be attributed to asymmetric and symmetric stretching of methylene groups $\left(-\mathrm{CH}_{2}-\right)$, while the bands at 1425 and $1160 \mathrm{~cm}^{-1}$ were attributed to deformation vibration of hydroxyl groups and the stretching of $\mathrm{C}-\mathrm{O}$ groups from the dimer in carboxylic acid. A strong band at $1739 \mathrm{~cm}^{-1}$ was attributed to asymmetric and symmetric stretching of the ester bond carbonyl group $(-\mathrm{O}-\mathrm{C}=\mathrm{O})$ introduced by succinylation (Gurgel et al., 2008). These bands confirmed the incorporation of succinic anhydride through ester linkages with a consequent release of carboxylic acid groups. 


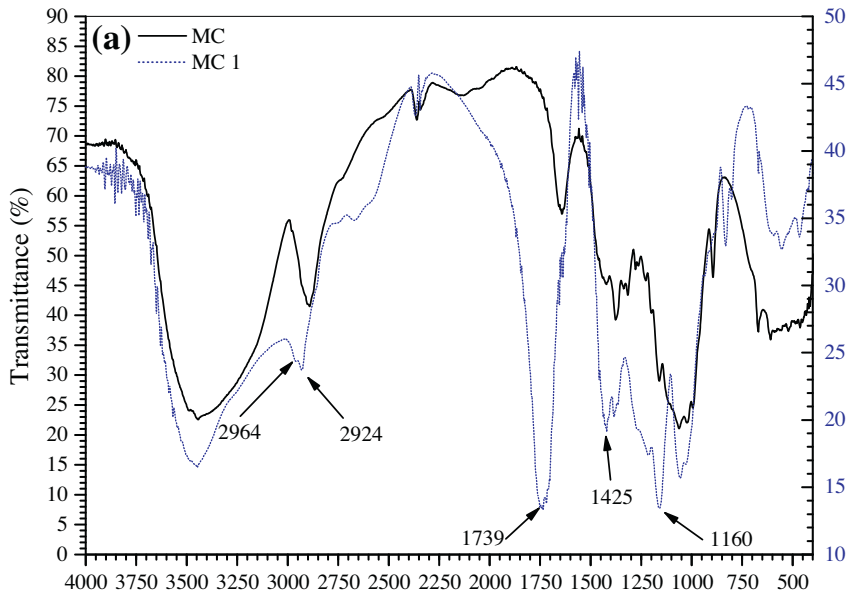

Wavenumber $\left(\mathrm{cm}^{-1}\right)$

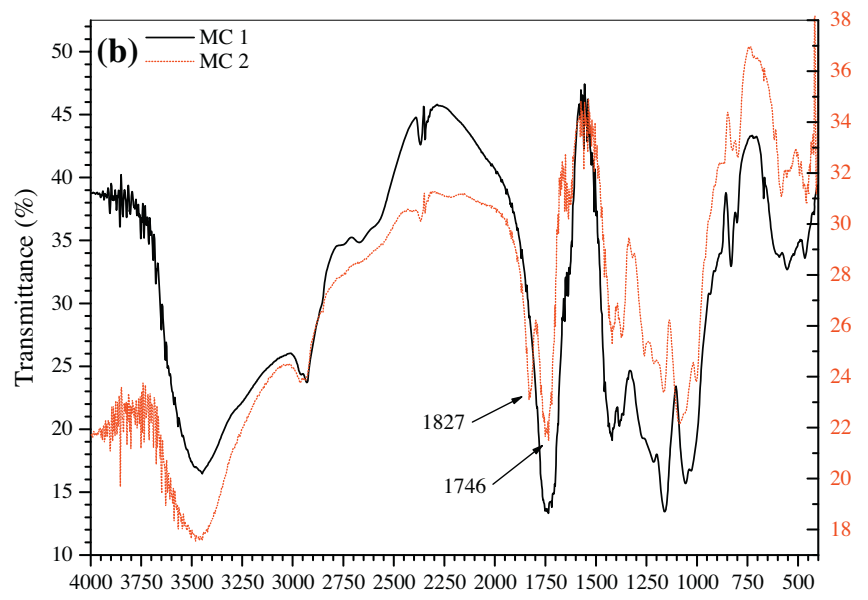

Wavenumber $\left(\mathrm{cm}^{-1}\right)$

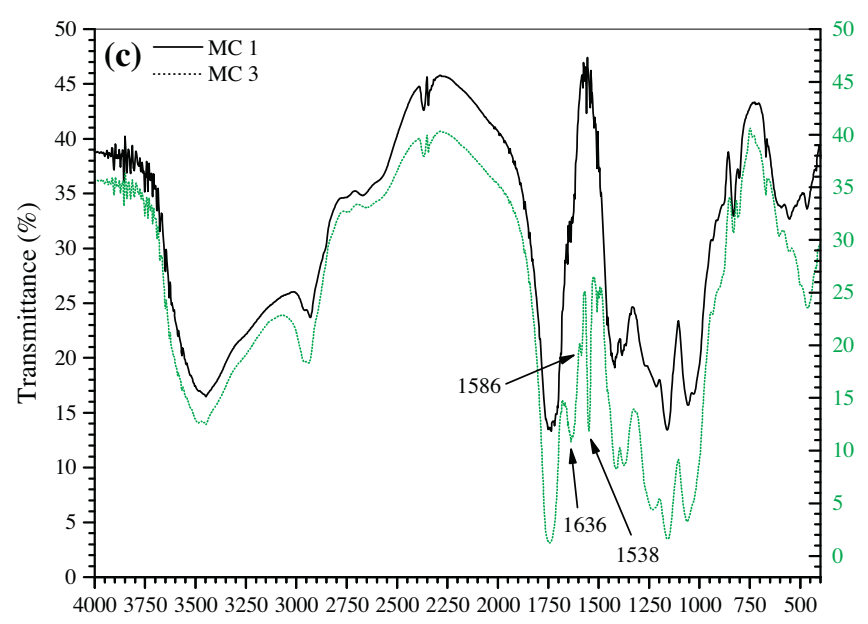

Wavenumber $\left(\mathrm{cm}^{-1}\right)$

Fig. 2. (a) FTIR spectra of $M C$ and $M C 1$, (b) MC 1 and $M C 2$, and (c) MC 1 and MC 3.

\subsubsection{Synthesis and characterization of $M C 2$}

Succinylated mercerized cellulose (MC 1) was reacted with acetic anhydride (solvent and dehydrating agent) to promote the formation of internal anhydride functional groups from carboxylic acid groups, yielding MC 2 . These internal anhydride groups were excellent electrophiles capable of reacting with nucleophilic groups such as the primary hydroxyl groups of riboflavin, which were better nucleophiles than secondary hydroxyl groups (Fig. 1b). In this study, the nucleophile was the primary hydroxyl group riboflavin and the reaction of riboflavin with MC 2 allowed incorporation of riboflavin onto the solid support through formation of an ester bond.

The synthesis of MC 2 was confirmed through FTIR analysis and the spectra of MC 2 and MC 1 are shown in Fig. 2b. When comparing the spectrum of MC 2 to the spectrum of MC 1, the appearance of bands at 1827 and $1746 \mathrm{~cm}^{-1}$ were attributed to the formation of carboxylic acid anhydride functional groups. In general, these two bands were separated by a maximum wavelength range of $81 \mathrm{~cm}^{-1}$ which is characteristic of the presence of a functional anhydride group (Nakanishi and Solomon, 1977). The changes seen in the spectrum of MC 2 (with respect to MC 1) confirmed the formation of internal anhydride functional groups on the solid support.

\subsubsection{Synthesis and characterization of $M C 3$}

MC 3 was obtained by the reaction of MC 2 with riboflavin using DMF as the solvent. The concentration of riboflavin chemically bonded to MC 3 was assessed by hydrolyzing the ester bond in an aqueous solution at $\mathrm{pH} 12$ (Fig. 1c) and quantifying lumiflavin (a riboflavin byproduct at pH 12, Fig. 1c). Analysis indicated a lumiflavin concentration in the supernatant of $44.19 \mathrm{mg} / \mathrm{L}$, and considering all lumiflavin in the supernatant was released by hydrolysis of MC 3, riboflavin content was $71.3 \mathrm{mg} / \mathrm{g}$.

MC 3 was characterized by infrared spectroscopy with FTIR, ${ }^{13} \mathrm{C}$ NMR and elemental analysis. The FTIR spectra of MC 1 and MC 3 are shown in Fig. 2c, where the three bands at 1548; 1586 and $1636 \mathrm{~cm}^{-1}$ were due to the incorporation of riboflavin. Abe et al. (1986) studied the infrared spectra of riboflavin and its derivatives, indicating the bands at 1552,1580 and $1583 \mathrm{~cm}^{-1}$ could be attributed to stretching vibrations of $\mathrm{C}_{24}=\mathrm{N}_{25}$ and $\mathrm{C}_{19}=\mathrm{N}_{20}$ bonds in the isoalloxazin unit rings (see Fig. 3), while the band at $1636 \mathrm{~cm}^{-1}$ was due to vibrations in the frequency of the isoalloxazin ring carbonyl group $\left(\mathrm{C}_{23}=\mathrm{O}\right)$.

The elemental analysis for MC 1 and MC 3 revealed carbon, hydrogen, and nitrogen contents of 43.71 and 35.04\%, 5.20 and $3.99 \%$, and 0.27 and $2.25 \%$, respectively. These results showed an increase in nitrogen content after modification of MC 1 with riboflavin to produce MC 3, which confirmed the incorporation of riboflavin into cellulosic matrix. The solid-state ${ }^{13} \mathrm{C} N M R(C P / M A S)$ spectrum of MC 3 is shown in Fig. 3. The ${ }^{13} \mathrm{C}$ NMR spectra of MC 3 exhibited chemical shifts attributed to the presence of cellulose and riboflavin in the chemical structure of this material (Keller et al., 1983; Melo et al., 2011). The signals at 105 and 90 ppm were related to the involvement of the $C-1$ and $C-4$ carbons (respectively) in the acetal bond of the $\beta(1 \rightarrow 4)$-D-glucopiranose units of cellulose. The signal at $75 \mathrm{ppm}$ was attributed to secondary carbons bonded to the hydroxyl groups of riboflavin (C-14, C-15, and C-16), cellulose (C-2 and C-3) and to the tertiary carbon of the cellulose structure (C-5). As a consequence of succinylation, the modified cellulose contained ester bonds formed after esterification of the primary hydroxyl groups in the glucopiranose units of cellulose. Thus, the signal at 66 ppm was related to the $C-6$ of cellulose, whereas the signal at $175 \mathrm{ppm}$ was attributed to carbonyl groups at C- $1^{\prime}, \mathrm{C}-4^{\prime}, \mathrm{C}-8$, and $C-11$. Additionally, the signal at $66 \mathrm{ppm}$ indicated the $\mathrm{C}-13$ from riboflavin, which was involved in the ester bond linking riboflavin to the succinylated cellulose through the primary hydroxyl groups of riboflavin at $\mathrm{C}-13$. The carbons in the riboflavin aromatic rings appeared as broad signals from 110 to $150 \mathrm{ppm}$, while the chemical shifts at $125,137,155$, and $160 \mathrm{ppm}$ were related to the presence of aromatic rings in the chemical structure of MC 3 , which indicated the chemical modification of MC 2 to bind riboflavin. These data and published studies evaluating succinylated cellulose (Gurgel and Gil, 2009; Melo et al., 2011) clearly demonstrated the incorporation of riboflavin onto cellulose through the formation of ester bonds. 


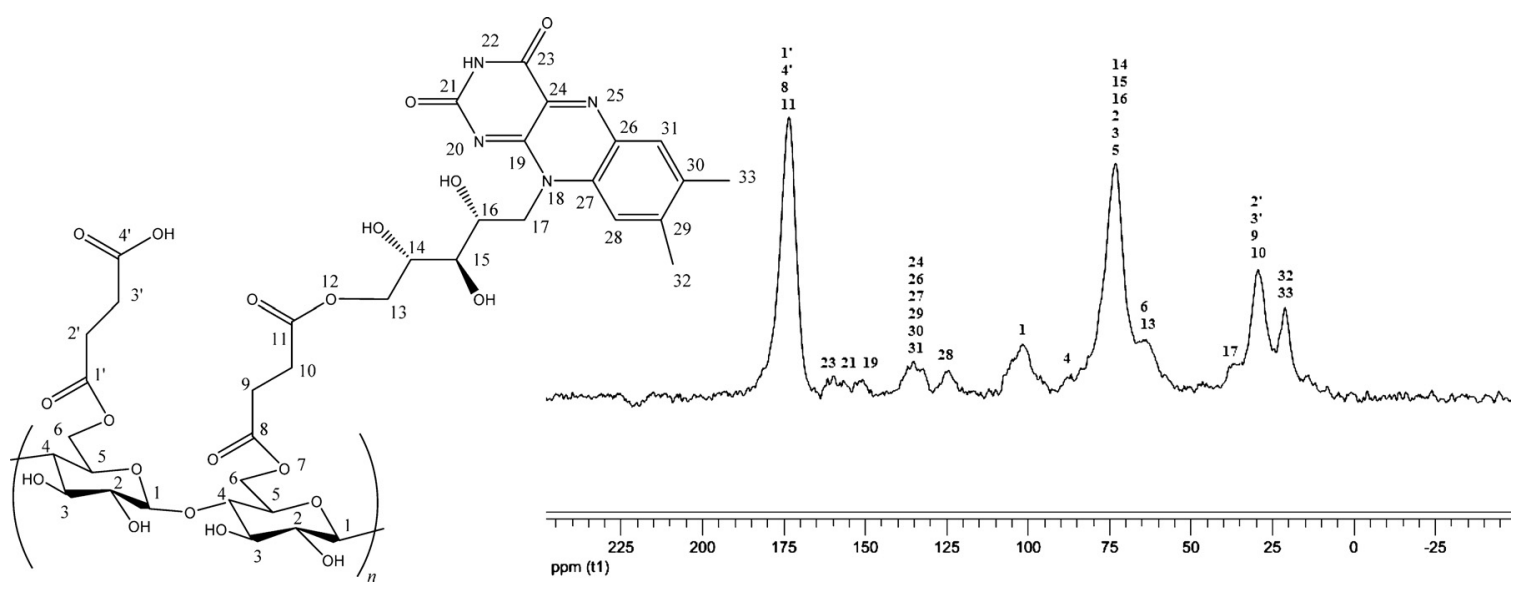

Fig. 3. Solid-state ${ }^{13} \mathrm{C} C \mathrm{CP} / \mathrm{MAS}$ NMR spectrum of MC 3 .

\subsection{Evaluation of the stability of $M C 3$ as a function of $p H$}

MC 3 was treated with an aqueous $\mathrm{HCl}$ solution $(\mathrm{pH}=2)$ for $24 \mathrm{~h}$, and no signal was seen at $267 \mathrm{~nm}$ for the washes, which confirmed the ester bond used to attach riboflavin onto MC 3 was not cleaved at $\mathrm{pH} 2$ ( $\mathrm{MC} 3$ was stable at $\mathrm{pH} \geq 2$ ). Treatment of $\mathrm{MC} 3$ with an aqueous $\mathrm{NaOH}$ solution $(\mathrm{pH}=9)$ for $24 \mathrm{~h}$ also showed no signal at $354 \mathrm{~nm}$ in the washes. However, at pH 11 and 12, the ester bond was hydrolyzed, which could be verified by the appearance of peaks at $354 \mathrm{~nm}$ in the washings. These observations indicated the ester bond used to attach riboflavin onto MC 3 was stable at pH 2-9.

\subsection{Influence of the reaction medium on the stability of MC 3}

Experiments were carried out to evaluate the influence of the reaction medium on MC 3 stability, and were performed in the presence of all components of the reaction medium with exception of RGY-RNL. No riboflavin was released from MC 3 (by hydrolysis of ester bond) under the experimental conditions used (Table 2). If a release had occurred, there would have been an increase in absorbance over time for the supernatants of experiment 2 (MC 3 was added). The absorbance of supernatants from experiment 3 was twice as high as those observed in experiment 2, which indicated that if riboflavin were released, it would have been detected.

\subsection{Influence of the reaction medium on degradation of RGY-RNL dye}

These experiments were carried out to evaluate RGY-RNL removal by adsorption onto anaerobic sludge and/or reaction with medium components. Adsorption of the RGY-RNL dye onto anaerobic sludge (experiment 7), MC 3 (experiment 6) or medium components (experiment 5) did not result in significant decolorization. Reasonable dye (color) removal only occurred in experiment

Table 2

Influence of reaction medium on the stability of MC 3 .

\begin{tabular}{llll}
\hline Experiment $^{\mathrm{a}}$ & \multicolumn{2}{l}{ Absorbance $(267 \mathrm{~nm})$} & $t=48 \mathrm{~h}$ \\
\cline { 2 - 4 } & $t=0 \mathrm{~h}$ & $t=24 \mathrm{~h}$ & 0.215 \\
$1^{\mathrm{b}}$ & 0.224 & 0.217 & 0.238 \\
$2^{\mathrm{c}}$ & 0.252 & 0.216 & 0.492 \\
$3^{\mathrm{d}}$ & 0.504 & 0.470 &
\end{tabular}

a All experiments were carried out with anaerobic sludge and without RGY-RNL.

b Control flasks, incubated without MC 3.

c Experiments carried out with MC 3.

d Experiments carried out with riboflavin instead of MC 3.
4 due to RGY-RNL reduction by anaerobic microorganisms in the absence of a redox mediator.

\subsection{Anaerobic degradation of RGY-RNL dye using $M C 3$ as the redox mediator}

In addition to the experiments evaluating anaerobic degradation of RGY-RNL dye using MC 3 as redox mediator (experiment 10), experiments using redox mediators such as soluble riboflavin (experiment 11) and yeast extract (experiment 9) were performed. The effect of each redox mediator on the decolorization of RGY-RNL in an anaerobic system is shown in Fig. 4.

According to dos Santos (2005), color removal of azo dyes in anaerobic systems without the addition of redox mediators varies from 60 to $80 \%$. Corrêa et al. (2009) reported that color removal efficiencies of the azo dye blue Drimarem HF-RL in anaerobic systems varies $39-45 \%$ within the first $24 \mathrm{~h}$, with a final degradation efficiency of $91 \%$ after $150 \mathrm{~h}$. van der Zee et al. (2001a) reported a $30 \%$ color removal efficiency in a bench-scale UASB reactor kept at $30^{\circ} \mathrm{C}$ without redox mediators and fed with the azo dye reactive red (RR2), while a 95\% color removal efficiency was seen for different azo dyes in anaerobic systems in less than 6 days (van der Zee et al., 2001b).

In this study, removal efficiency of RGY-RNL by anaerobic biomass in the absence of RM was 30.7\% within the first $24 \mathrm{~h}$ and

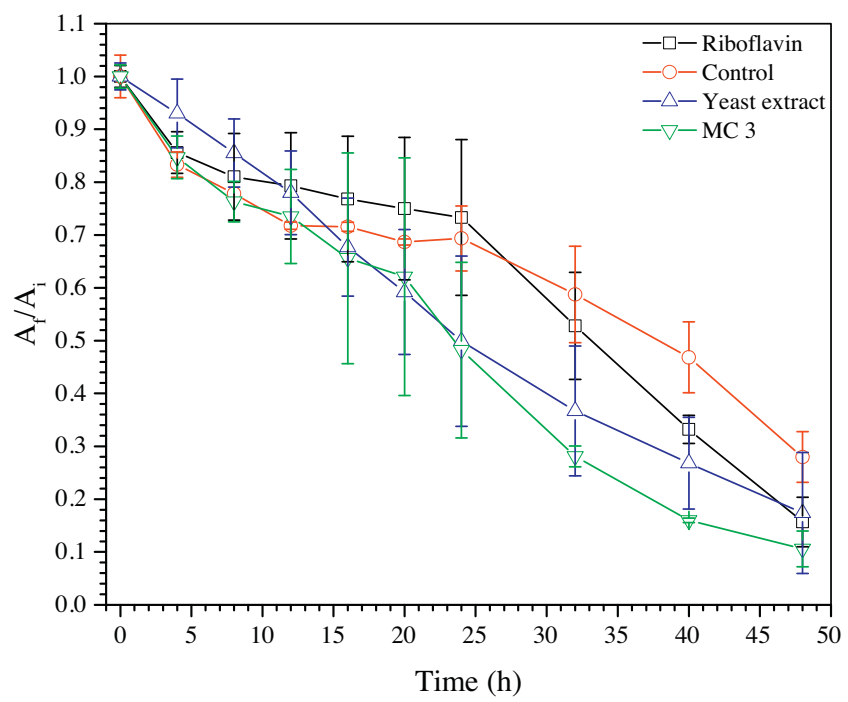

Fig. 4. Anaerobic degradation of azo dye RGY-RNL using different redox mediators. 
$72.1 \%$ after $48 \mathrm{~h}$ in batch mode at $25^{\circ} \mathrm{C}$, which were in agreement with results reported by dos Santos (2005). It should be noted that the maximum removal efficiency in this study was seen after $48 \mathrm{~h}$, while over $144 \mathrm{~h}$ of degradation time was required in the study of Corrêa et al. (2009).

The use of redox mediators such as anthraquinone sulfonate (AQS), disulfonated anthraquinone (AQDS), yeast extract, and riboflavin (among others) have led to significant improvements in azo dye removal kinetics under anaerobic conditions (Baêta et al., 2012; Corrêa et al., 2009; Costa et al., 2010; Field and Brady, 2003; dos Santos, 2005). Costa et al. (2010) reported a 2.27-fold increase in the degradation kinetic rate constant for reactive red 2 (RR2) azo dye in anaerobic reactors fed with AQDS. van der Zee et al. (2001a) demonstrated an increase in color removal from $30 \%$ to $88 \%$ by adding AQDS as the catalyst in an anaerobic system used for the degradation of RR2 dye. dos Santos (2005) found a 2.9-fold increase in the RR2 color removal rate in reaction flasks that received AQS when compared to flasks without. When yeast extract was used as the redox mediator (riboflavin) in the degradation of blue azo dye Drimaren HF-RL, Corrêa et al. (2009) and Baêta et al. (2012) report color removal efficiencies up to $87 \%$ within the first $24 \mathrm{~h}$ of degradation, and a final removal efficiency higher than $90 \%$ after $150 \mathrm{~h}$. Field and Brady (2003) found the degradation rate of Yellow mordant 10 dye increases $61 \%$ with the addition of riboflavin in anaerobic systems operating in batch mode.

RGY-RNL color removal efficiency increased from 30.7 to $50.1 \%$ within the first $24 \mathrm{~h}$ after addition of yeast extract (source of the redox mediator riboflavin), which increased to $82.6 \%$ after $48 \mathrm{~h}$. When riboflavin was added, degradation of RGY-RNL dye was $26.7 \%$ within the first $24 \mathrm{~h}$, which increased to $84.3 \%$ after $48 \mathrm{~h}$. These results were similar to those reported by Corrêa et al. (2009) for the same times of dye degradation. Possible explanations for the differences between the results of this study and those reported in literature may due to factors such as the chemical structure of the dyes used in the experiments, the ratio of dye to redox mediator (can cause differences in the transfer rate of electrons between RM and dye) and even the electron donors used.

The degradation rate constant for RGY-RNL dye using MC3 was improved by 1.56 -fold when compared with experiments without addition of redox mediators and followed the zero-order kinetic model. This result is similar to those reported in the literature. Several authors evaluated the use of immobilized redox mediators to improve the kinetics of azo dye decolorization in anaerobic treatment systems. Three factors are important to compare various reducing systems using immobilized redox mediators such as type of solid support, redox mediator for immobilization, and the structure of dyes. Cervantes et al. (2010) has improved the dye removal rate constant of methyl orange by 8.8 -fold using NQS immobilized onto ion exchange R1 type resin and by 1.9 -fold using NQS immobilized onto ion exchange R2 type resin. AQDS immobilized to nanoparticles of $\mathrm{Al}(\mathrm{OH})_{3}$ also improved the dye degradation rate constant for reactive red 2 (RR2) by 7.5-fold, while AQDS immobilized onto ion exchange resin improved the dye degradation constant 1.9-fold (Alvarez et al., 2010). Humic substances (HS) attached to ion exchange resin (AER) increase degradation rates for RR2 by 2-fold (Cervantes et al., 2011). Martínez et al. (2013) reported the degradation of RR2 using immobilized HS supported on an AER in an upflow anaerobic sludge reactor (UASB). The decolorization efficiency of RR2 increased $\sim 90 \%$ in comparison with the control UASB reactor operated without immobilized HS. Amezquita-Garcia et al. (2014) investigated the anchorage of two anthraquinones (AAQ and AQDS) on surface of polyacrilonitrile activated carbon fibers (ACFs) to obtain materials with redox functional groups on their surface to be applied for the treatment of contaminants with electron withdrawing groups. These authors reported that only AQDS anchored on ACFs was an effective redox mediator improving the reductive conversion of 4-nitrophenol (4NP) to 4-aminophenol. The catalytic properties of AQDS-ACFs improved the reduction of $4 \mathrm{NP}$ by $49 \%$ in comparison with ACFs alone. Many studies have shown the influence of the structure of dyes in the anaerobic reduction process using immobilized redox mediators. Yuan et al. (2012) have immobilized AQS on ceramsites and found an increase of degradation rate constant for Acid dye yellow 36 (AY36) by 8.0-fold, while for RR2, Acid red 27 (AR27), and Acid orange 7 (AO7), the increases in degradation rate were $2.3,2.7$, and 2.8 -fold, respectively, when compared to experiments carried out without redox mediator. Guo et al. (2007) reported that anthraquinone immobilized on calcium alginate beads had an increase in decolorization rates for reactive brilliant red $\mathrm{K}-2 \mathrm{BP}$, reactive brilliant red $\mathrm{X}-3 \mathrm{~B}$, acid black $10 \mathrm{~B}$, acid scarlet $\mathrm{GR}$, acid red $B$ and Acid red G of 1.5-2, 1.57, 1.88, 2.1, 1.65, and 1.48-fold, respectively. Lu et al. (2010) also reported AQS immobilization on polyurethane foam (PUF) and found an increase in degradation rates for RR2 by 4-fold, while Zhou et al. (2014) investigated decolorization of Reactive red $\mathrm{K}-2 \mathrm{G}$ using AQS immobilized on PUF in an upflow anaerobic bioreactor. These authors reported improvements in decolorization efficiencies by 1.47 -fold in comparison with the control.

The results obtained in this study indicated a removal efficiency of $51.8 \%$ for anaerobic degradation of RGY-RNL dye in the presence of riboflavin immobilized onto MC 3 after $24 \mathrm{~h}$ of incubation. This result was similar to those experiments using yeast extract as the source of redox mediators (50.1\%), twice as high as when soluble riboflavin was used (26.7\%), and higher than those which did not receive any redox mediator (control flasks, 30.7\%). After $48 \mathrm{~h}$, the color removal efficiency in the flasks without redox mediator was $72.1 \pm 0.1$ and $89.4 \pm 0.0 \%$ for those incubated with MC 3, which was higher than when yeast extract (82.6\%) and riboflavin (84.3\%) were used as redox mediators.

In comparison to other studies on azo dyes such as RR2 (van der Zee et al., 2001a) and Blue Drimaren HF-RL (Corrêa et al., 2009) which were degraded anaerobically for $24 \mathrm{~h}$ without redox mediators, the percentages of color removal obtained in this study in the presence of MC 3 were significantly higher. This study indicated MC 3 was as efficient as riboflavin and yeast extract in the anaerobic decolorization of RGY-RNL, and could be employed for the anaerobic degradation of other azo dyes.

In order to provide evidence of the reduction process of the RGY-RNL dye mediated by immobilized riboflavin derivative (MC 3 ) through the azo cleavage, the released aromatic amines were analyzed by HPLC. According to Pinheiro et al. (2004), the degradation of azo dyes containing sulfonic acid groups such as the model dye used in this study generates as byproducts aromatic amines with sulfonic groups such as analogous of sulfanilic acid. Baêta et al. $(2015,2013)$ have studied the anaerobic degradation of RGY-RNL dye with powdered activated carbon and evaluated the byproducts released. The possible degradation byproducts of RGY-RNL dye were evaluated as sulfanilic acid derivatives (Baêta et al., 2013). Fig. 5 shows the chromatograms of samples collected from anaerobic degradation experiments, which were carried out in the same conditions described in Section 2.2.8. These experiments were accomplished with and without (control) addition of MC 3. Standards solutions of sulfanilic acid and volatile fatty acids (VFA) (intermediates in anaerobic digestion) (Baêta et al., 2013) were also analyzed by HPLC. The nature of byproducts generated in the experiments of anaerobic degradation of RGY-RNL dye was suggested by comparing retention times of the standard solution of sulfanilic acid and samples subjected to anaerobic degradation using MC 3 as RM (Fig. 5). The retention time of sulfanilic acid was very close to those aromatic amines released in the anaerobic degradation of RGY-RNL dye in the presence of MC 3. Similar observations were reported by Baêta et al. (2013) for the anaerobic degradation of RGY-RNL in an 


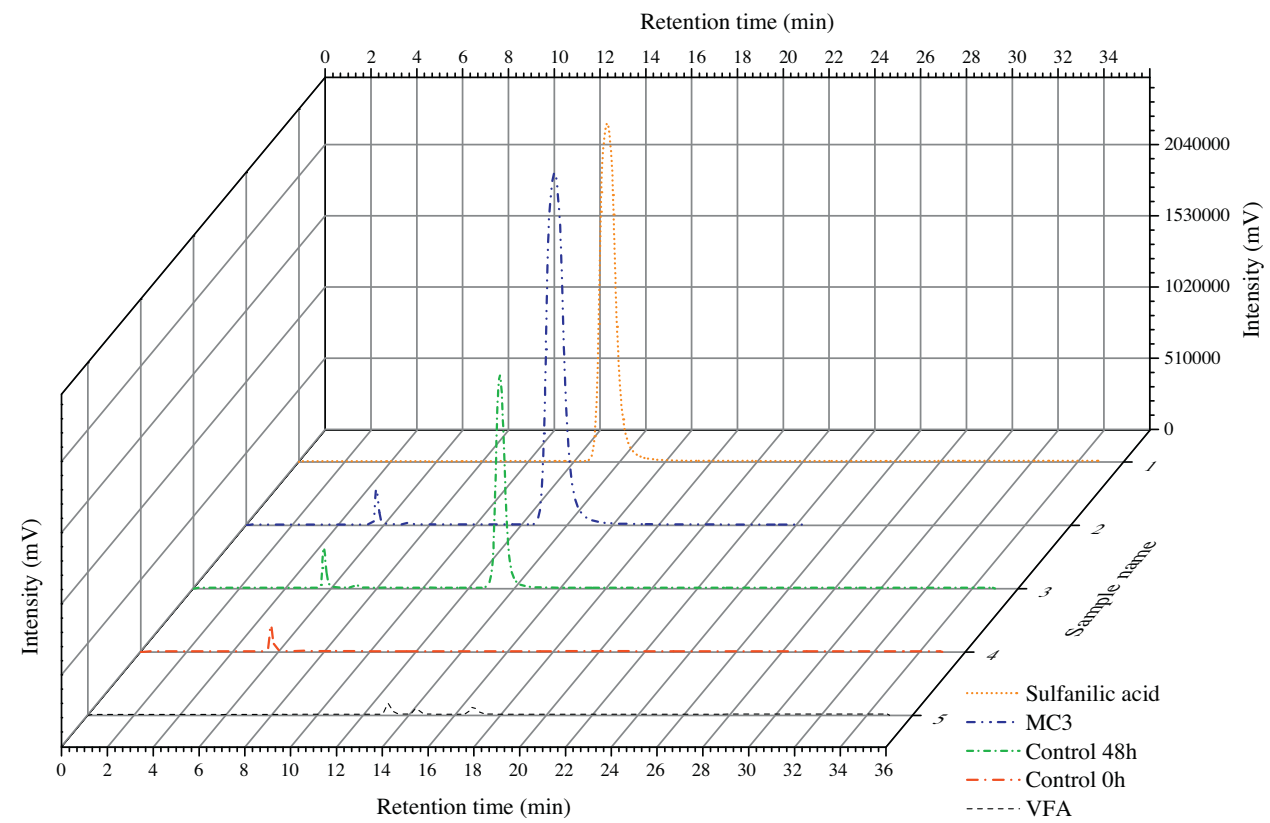

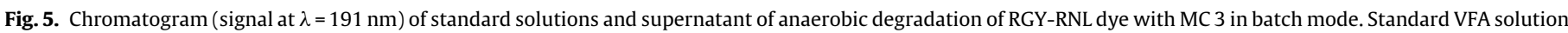
(5); control $0 \mathrm{~h}$ (4); control $48 \mathrm{~h}$ (3); MC 3 (2), and standard sulfanilic acid solution (1).

Table 3

Parameters obtained from the linear fit for zero-order and first-order kinetic models for anaerobic degradation of RGY-RNL.

\begin{tabular}{|c|c|c|c|c|c|}
\hline Experiment & Kinetic model & $R^{2}$ & $k_{0, \mathrm{obs}}(\mathrm{mg} / \mathrm{Lh})$ & $k_{1, \mathrm{obs}}\left(\mathrm{h}^{-1}\right)$ & $t_{1 / 2}(\mathrm{~h})$ \\
\hline Control & Zero-order & 0.9291 & 0.0121 & - & 41.3 \\
\hline MC 3 & Zero-order & 0.9826 & 0.0189 & - & 26.4 \\
\hline Riboflavin & Zero-order & 0.9369 & 0.0158 & - & 31.6 \\
\hline Yeast extract & First-order & 0.9822 & - & 0.0364 & 19.0 \\
\hline
\end{tabular}

upflow UASB reactor using yeast extract and powdered activated carbon as sources of redox mediators. The azo cleavage of RGY-RNL using MC 3 resulted in the formation of a large amount of sulfanilic acid derivatives than those experiments performed without MC 3 (Fig. 5). This observation proves the efficiency of MC 3 to enhance the electron transfer rate in the reduction of azo bond.

The chemical stability is an important characteristic of an immobilized redox mediator. Most of the studies reported in the literature are related to the immobilization of quinone-based redox mediators on solid supports such as ion exchange resins, calcium alginate, and nanoparticles of metal oxides through adsorption, electrostatic interaction and entrapment techniques and yielded good mechanical strengths during the removal process (Alvarez et al., 2010; Cervantes et al., 2010, 2011; Guo et al., 2007; Martínez et al., 2013). In this study, the mediator redox riboflavin was immobilized on cellulose by a covalent bond. A chemical bond is considered a stronger bond for incorporation of a redox mediator on solid support than immobilization by adsorption, for example. Therefore, the attachment of riboflavin on cellulose can provide good mechanical and chemical properties to this solid support to resist for the anaerobic degradation process. Lu et al. (2010) and Yuan et al. (2012) adopted a similar strategy for the immobilization of redox mediators on polyurethane foam and ceramsite, respectively.

Anaerobic degradation of RGY-RNL dye as a function of time was evaluated using three kinetic models: zero-order, first-order and second-order. Experiments performed without redox mediators (control) and with MC 3 as the redox mediator followed the zero-order kinetic model. Similar results were reported by Field and Brady (2003), where riboflavin was used as the redox mediator in the anaerobic reduction of azo dye mordant yellow 10 , where the zero-order kinetic model explained the experimental data. Table 3 summarizes the kinetic results.

The use of MC 3 as the redox mediator increased the zero-order degradation rate constant $\left(k_{0, \mathrm{obs}}\right)$ of RGY-RNL 1.56 -fold compared to control (Table 3 ), which was similar to the $k_{0, \text { obs }}$ reported by Field and Brady (2003) for anaerobic degradation of Mordant yellow 10 in the presence of riboflavin. Despite this increase, the color removal rate was lower than those reported in the literature for immobilized redox mediators (Alvarez et al., 2010; Cervantes et al., 2010; Lu et al., 2010). However, the comparison was not straightforward, since Cervantes et al. (2010) and Lu et al. (2010) immobilized different redox mediators (AQDS, humic substances and NQS) on different supports to degrade a different azo dye (RR2).

Summarizing the results obtained in this study, MC 3 was as efficient as riboflavin and yeast extract in the anaerobic decolorization of RGY-RNL dye, and therefore, it could be employed for the anaerobic degradation of other azo dyes. An advantage of MC 3 in relation to riboflavin and yeast extract is that MC 3 can be recovered and reused in the anaerobic degradation process.

\section{Conclusions}

The results have shown that riboflavin was covalently bound to cellulose and the resulted material (MC3) was chemically stable at $\mathrm{pH} 2$ to 9, covering the $\mathrm{pH}$ range for anaerobic microorganisms. It was demonstrated that degradation of RGY-RNL was not due to adsorption or chemical reduction. The use of MC 3 increased the RGY-RNL degradation rate constant by $56 \%$, which was similar when riboflavin or yeast extract were used as redox mediators. The zero-order kinetic model best described the decolorization process 
in the presence of MC 3. The use of immobilized redox mediators as MC 3 could allow reduction of wastewater treatment costs.

\section{Acknowledgements}

The authors are grateful to the Universidade Federal de Ouro Preto (UFOP), Fundação de Amparo à Pesquisa do Estado de Minas Gerais (FAPEMIG, grant number CEX APQ-01356/09), Conselho Nacional de Desenvolvimento Científico e Tecnológico (CNPq, grant number 471863/2009-2), and Coordenação de Aperfeiçoamento de Pessoal de Nível Superior (CAPES) for funding this research.

\section{Appendix A. Supplementary data}

Supplementary data associated with this article can be found, in the online version, at http://dx.doi.org/10.1016/j. indcrop.2014.10.059.

\section{References}

Abe, M., Kyogoku, Y., Kitagawa, T., Kawano, K., Ohishi, N., Takai-Suzuki, A., Yagi, K., 1986. Infrared spectra and molecular association of lumiflavin and riboflavin derivatives. Spectrochim. Acta. A. Mol. Biomol. Spectrosc. 42, 1059-1068.

Alvarez, L.H., Perez-Cruz, M.A., Rangel-Mendez, J.R., Cervantes, F.J., 2010. Immobilized redox mediator on metal-oxides nanoparticles and its catalytic effect in a reductive decolorization process. J. Hazard. Mater. 184, 268-272.

Amezquita-Garcia, H.J., Razo-Flores, E., Cervantes, F.J., Rangel-Mendez, J.R., 2014. Anchorage of anthraquinone molecules onto activated carbon fibers to enhance the reduction of 4-nitrophenol. J. Chem. Technol. Biotechnol., http://dx.doi.org/10.1002/jctb.4478 (in press).

Aquino, S.F., Chernicharo, C.A.L., Foresti, E., Santos, M.L.F, Monteggia, L.O., 2007. Metodologias para determinação da atividade metanogênica específica (AME) em lodos anaeróbios. Eng. Sanit. Ambient. 12, 192-201.

Baêta, B.E., Aquino, S.F., Silva, S.Q., Rabelo, C.A., 2012. Anaerobic degradation of azo dye Drimaren blue HFRL in UASB reactor in the presence of yeast extract a source of carbon and redox mediator. Biodegradation 23, 199-208.

Baêta, B.E.L., Lima, D.R.S., Silva, S.Q., Aquino, S.F., 2015. Evaluation of soluble microbial products and aromatic amines accumulation during a combined anaerobic/aerobic treatment of a model azo dye. Chem. Eng. J. 259, 936-944.

Baêta, B.E.L., Luna, H.J., Sanson, A.L., Silva, S.Q., Aquino, S.F., 2013. Degradation of a model azo dye in submerged anaerobic membrane bioreactor (SAMBR) operated with powdered activated carbon (PAC). J. Environ. Manage. 128, 462-470.

Cervantes, F.J., Garcia-Espinosa, A., Moreno-Reynosa, M.A., Rangel-Mendez, J.R., 2010. Immobilized redox mediators on anion exchange resins and their role on the reductive decolorization of azo dyes. Environ. Sci. Technol. 44, 1747-1753.

Cervantes, F.J., Gonzalez-Estrella, J., Márquez, A., Alvarez, L.H., Arriaga, S., 2011. Immobilized humic substances on an anion exchange resin and their role on the redox biotransformation of contaminants. Bioresour. Technol. 102, 2097-2100.

Chernicharo, C.A.L., 2007. Princípios do Tratamento Biológico de Águas Residuárias Reatores anaeróbicos, second ed. Departamento de Engenharia Sanitária e Ambiental, Universidade Federal de Minas Gerais, Minas Gerais.

Clesceri, L.S., Eaton, A.D., Greenberg, A.E., Association, A.P.H., Association, A.W.W. Federation, W.E., 1998. Standard Methods for the Examination of Water and Wastewater. American Public Health Association, Washington, DC.

Corrêa, C.A.R, Aquino, S.F., Caldas, P.C.P., Silva, S.Q., 2009. Uso de extrato de levedura como fonte de carbono e de mediadores redox, para a degradação anaeróbia de corante azo. Eng. Sanit. Ambient. 14, 559-568.

Costa, M.C., Mota, S., Nascimento, R.F., Dos Santos, A.B., 2010. Anthraquinone-2,6disulfonate (AQDS) as a catalyst to enhance the reductive decolourisation of the azo dyes Reactive Red 2 and Congo Red under anaerobic conditions. Bioresour. Technol. 101, 105-110.

dos Santos, A.B., 2005. Aplicação conjunta de tratamento anaeróbio termofílico por lodo granular e de mediadores redox na remoção de cor de águas residuárias têxteis. Eng. Sanit. Ambient. 10, 253-259.

dos Santos, A.B., Bisschops, I.A., Cervantes, F.J., van Lier, J.B., 2004. Effect of different redox mediators during thermophilic azo dye reduction by anaerobic granular sludge and comparative study between mesophilic (30 degrees $\mathrm{C}$ ) and thermophilic (55 degrees $\mathrm{C}$ ) treatments for decolourisation of textile wastewaters. Chemosphere 55, 1149-1157.

dos Santos, A.B., Cervantes, F.J., van Lier, J.B., 2007. Review paper on current technologies for decolourisation of textile wastewaters: perspectives for anaerobic biotechnology. Bioresour. Technol. 98, 2369-2385.

Field, J.A., Brady, J., 2003. Riboflavin as a redox mediator accelerating the reduction of the azo dye mordant yellow 10 by anaerobic granular sludge. Water Sci. Technol. 48, 187-193 (A Journal of the International Association on Water Pollution Research).

Guo, J., Zhou, J., Wang, D., Tian, C., Wang, P., Salah Uddin, M., Yu, H., 2007. Biocalalyst effects of immobilized anthraquinone on the anaerobic reduction of azo dyes by the salt-tolerant bacteria. Water Res. 41, 426-432.

Gurgel, L.V.A., Gil, L.F., 2009. Adsorption of $\mathrm{Cu}(\mathrm{II}), \mathrm{Cd}(\mathrm{II})$, and $\mathrm{Pb}(\mathrm{II})$ from aqueous single metal solutions by succinylated mercerized cellulose modified with triethylenetetramine. Carbohydr. Polym. 77, 142-149.

Gurgel, L.V.A., Junior, O.K., Gil, R.P.D.F., Gil, L.F., 2008. Adsorption of $\mathrm{Cu}(\mathrm{II}), \mathrm{Cd}(\mathrm{II})$ and $\mathrm{Pb}(\mathrm{II})$ from aqueous single metal solutions by cellulose and mercerized cellulose chemically modified with succinic anhydride. Bioresour. Technol. 99 3077-3083.

Karnitz, O., Gurgel, L.V.A., de Melo, J.C.P., Botaro, V.R., Melo, T.M.S., Gil, R.P.D.F., Gil, L.F., 2007. Adsorption of heavy metal ion from aqueous single metal solution by chemically modified sugarcane bagasse. Bioresour. Technol. 98, 1291-1297.

Keller, P.J., Le Van, Q., Bacher, A., Floss, H.G., 1983. Biosynthesis of riboflavin: ${ }^{13} \mathrm{C}-$ NMR techniques for the analysis of multiply ${ }^{13} \mathrm{C}$-labeled riboflavins. Tetrahedron 39, 3471-3481.

Lu, H., Zhou, J., Wang, J., Si, W., Teng, H., Liu, G., 2010. Enhanced biodecolorization of azo dyes by anthraquinone-2-sulfonate immobilized covalently in polyurethane foam. Bioresour. Technol. 101, 7196-7199.

Martínez, C., Celis, L., Cervantes, F., 2013. Immobilized humic substances as redox mediator for the simultaneous removal of phenol and Reactive Red 2 in a UASB reactor. Appl. Microbiol. Biotechnol. 97, 9897-9905.

Melo, J.C.P., Silva Filho, E.C., Santana, S.A.A., Airoldi, C., 2011. Synthesized cellulose/succinic anhydride as an ion exchanger. Calorimetry of divalent cations in aqueous suspension. Thermochim. Acta 524, 29-34.

Méndez-Paz, D., Omil, F., Lema, J.M., 2005. Anaerobic treatment of azo dye Acid Orange 7 under batch conditions. Enzyme Microb. Technol. 36, 264-272.

Nakanishi, K., Solomon, P.H., 1977. Infrared Absorption Spectroscopy, second ed Holden-Day, Inc., San Francisco, CA.

Penzkofer, A., 2012. Photoluminescence behavior of riboflavin and lumiflavin in liquid solutions and solid films. Chem. Phys. 400, 142-153.

Pinheiro, H.M., Touraud, E., Thomas, O., 2004. Aromatic amines from azo dye reduction: status review with emphasis on direct UV spectrophotometric detection in textile industry wastewaters. Dyes Pigm. 61, 121-139.

van der Zee, F.P., Bisschops, I.A., Blanchard, V.G., Bouwman, R.H., Lettinga, G., Field J.A., 2003. The contribution of biotic and abiotic processes during azo dye reduction in anaerobic sludge. Water Res. 37, 3098-3109.

van der Zee, F.P., Bouwman, R.H., Strik, D.P., Lettinga, G., Field, J.A., 2001a. Application of redox mediators to accelerate the transformation of reactive azo dyes in anaerobic bioreactors. Biotechnol. Bioeng. 75, 691-701.

van der Zee, F.P., Lettinga, G., Field, J.A., 2001b. Azo dye decolourisation by anaerobic granular sludge. Chemosphere 44, 1169-1176.

Yuan, S.-Z., Lu, H., Wang, J., Zhou, J.-T., Wang, Y., Liu, G.-F., 2012. Enhanced biodecolorization of azo dyes by quinone-functionalized ceramsites under saline conditions. Process Biochem. 47, 312-318.

Zhou, Y., Lu, H., Wang, J., Li, J., Zhou, J., Jin, R., 2014. Catalytic performance of functionalized polyurethane foam on the reductive decolorization of Reactive Red $\mathrm{K}-2 \mathrm{G}$ in up-flow anaerobic reactor under saline conditions. Bioprocess Biosyst. Eng., 1-11, http://dx.doi.org/10.1007/s00449-014-1252-z. 